\title{
Numerical modelling of wave downfall pressures on the deck landward of a vertical breakwater
}

\author{
Document Version \\ Accepted author manuscript
}

Link to publication record in Manchester Research Explorer

\section{Citation for published version (APA):}

Baines, A., Cunningham, L., \& Rogers, B. D. (2018). Numerical modelling of wave downfall pressures on the deck landward of a vertical breakwater. In K. Burgess (Ed.), ICE Coasts, Marine Structures and Breakwaters 2017: Realising the Potential (pp. 1051). ICE Publishing.

https://www.icevirtuallibrary.com/doi/full/10.1680/cmsb.63174.1051

Published in:

ICE Coasts, Marine Structures and Breakwaters 2017: Realising the Potential

\section{Citing this paper}

Please note that where the full-text provided on Manchester Research Explorer is the Author Accepted Manuscript or Proof version this may differ from the final Published version. If citing, it is advised that you check and use the publisher's definitive version.

\section{General rights}

Copyright and moral rights for the publications made accessible in the Research Explorer are retained by the authors and/or other copyright owners and it is a condition of accessing publications that users recognise and abide by the legal requirements associated with these rights.

\section{Takedown policy}

If you believe that this document breaches copyright please refer to the University of Manchester's Takedown Procedures [http://man.ac.uk/04Y6Bo] or contact uml.scholarlycommunications@manchester.ac.uk providing relevant details, so we can investigate your claim.

\section{OPEN ACCESS}




\title{
Numerical modelling of wave downfall pressures on the deck landward of a vertical breakwater.
}

\author{
Annelie Baines*, Lee S. Cunningham*, Benedict D. Rogers* \\ *School of Mechanical, Aerospace and Civil Engineering University of Manchester, \\ United Kingdom
}

\begin{abstract}
Storms and associated violent wave events have increased in frequency and intensity over the last number of years and this trend is set to continue in line with climate change and sea level rise predictions. Structures located directly landward of coastal structures are at risk from violent wave events and corresponding white-water overtopping. Depending on circumstances, experimental investigations into these effects may be expensive and difficult to undertake. This paper investigates the ability of Smoothed Particle Hydrodynamics (SPH), a particle-based simulation method, to model these kinds of violent wave events. With numerical simulations being generally economic and faster to complete, developing a numerical model such as the one proposed in this paper would give designers a powerful tool to help design structures located landward of coastal defences and the defences themselves. The work presented herein is aimed at demonstrating the ability of the SPH method to model violent wave events against vertical seawalls by comparing the results from the numerical model to those obtained experimentally. The pressure envelopes obtained from the numerical and experimental models show general agreement where the mean and median of the uprush velocities from the SPH simulations are within $7 \%$ of the experimental data, thus confirming the potential of the SPH approach for this application.
\end{abstract}

\section{Introduction}

In recent years, increased storm frequency and intensity has presented a severe challenge to shorebased structures (Arns et al. 2015; Committee on Climate Change 2017). Where previously coastal defences may have protected such structures from the effects of violent overtopping, many now find themselves vulnerable; the severe storms seen in the UK in 2014 and 2015 clearly illustrate the violence of such events (see Figure 1). When impacted by breaking waves, vertical coastal defence structures can experience significant horizontal impact forces. These forces have been analysed and many analytical equations exist that allow designers to predict the magnitude of these forces with reasonable and practicable certainty. The effects of such wave impacts are not limited to their respective horizontal forces and can cause large plumes of spray in overtopping. This kind of violent overtopping has direct implications for structures landward of the coastal defence. Comparatively little research has been done into quantifying these forces. Towards an understanding of this scenario, a series of large-scale experiments were carried out in the Large Wave Channel (GWK) at FZK in Hannover by Wolters et al. (2005). The results from the experiments indicate that the forces from near-breaking waves impacting on a vertical breakwater could generate downfall pressures on the deck of the structure of up to $12 \rho \mathrm{gH}_{i}$. The aforementioned results underline the importance of understanding and quantifying these forces for efficient and safe design of coastal structures. 


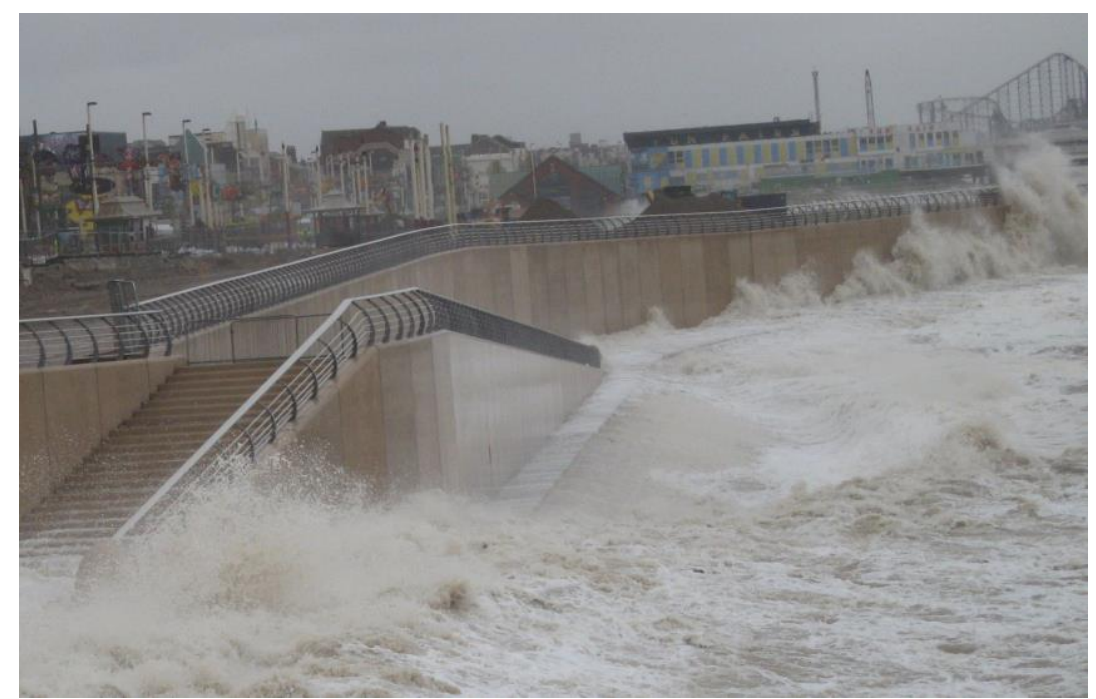

Figure 1 Violent wave breaking during a storm at Blackpool, UK (Cunningham \& Burgess 2012)

The fluid mechanics and physical processes involved in violent wave impacts and resulting spray overtopping are complex and difficult to capture experimentally. As will be discussed in this paper, these events usually occur over very short time periods making it difficult to fully capture the wave mechanics and behaviour. Numerical models offer the possibility to investigate in detail these effects. Such models are also more easily repeatable than experimental schemes as well as being generally more cost effective. The use of numerical models for the analysis of wave impacts has become relatively common in research with many different types of models being proposed. Shallow water equations coupled to Boussinesq modelling has been used to model overtopping of a vertical seawall (McCabe et al. 2013 \& 2014) Other models use Non Linear Shallow Water equations (NLSW) or are based on the Navier-Stokes equations, either Eulerian or Lagrangian. Further details on the range of numerical models used to model wave overtopping events can be found in the latest version of EurOtop (Van der Meer et al. 2016). However, few numerical models have been used to study the physical processes and forces involved in violent breaking waves. Extreme overtopping events usually involve highly non-linear flows and therefore are difficult to model using classic mesh-based CFD methods. Smoothed Particle Hydrodynamics (SPH) offers a numerical modelling technique that is capable of handling the violent, turbulent and non-linear aspects of these types of flows. Altomare et al. 2015 used a coupled SWASH - SPH model to investigate the impact forces from violent breaking waves on dikes and seawalls however it has yet to be applied to violent impacts resulting in spray dominated overtopping, (Altomare et al. 2015, Dominguez et al. 2014).

Smoothed Particle Hydrodynamics (SPH) is a Lagrangian fluid modelling technique which uses particles to represent the fluid. SPH solves the Navier-Stokes equation to compute the trajectory and interactions of the fluid particles. The fluid pressure, velocity and trajectories are calculated without special treatment being needed for the free surface. The absence of a mesh makes this an ideal method for the complex flows typical of breaking waves around seawalls and other coastal structures. Work by Dalrymple and Rogers (2006) demonstrated the capability of SPH to handle the complex flow phenomena of breaking waves, impact and propagations around coastal structures. More recent work has demonstrated the capacity of SPH, specifically the open-source DualSPHysics code used in this work (Crespo et al. 2015), to propagate wave fields accurately from offshore to nearshore thus allowing unprecedented detail in prediction of overtopping and impact behaviour from offshore wave conditions (Altomare \& Suzuki 2013). The ability of SPH to simulate fluid-structure impacts has been vigorously demonstrated by Marongiu et al. (2011), Marrone et al. (2011), Koukouvinis et al. (2013) for jets impacting walls, as well as the present authors Cunningham et al. (2014); Pringgana et al. (2016).

\section{Outline of the Paper}

The aim of this paper is to present a comparison between the experimental data obtained by Wolters et al. (2005) to the numerical results from SPH simulations. The next section gives an overview of the work relevant to designing for extreme overtopping and downfall pressures from breaking-wave impacts. Following this a detailed overview of the Hannover test case will be given. The next section 
will detail the setup of the numerical model followed by the results and comparison with the experimental results. Finally, the limitations and implications of this work will be discussed.

\section{Previous Work}

\section{Wave overtopping of Vertical Structures}

Much research has investigated wave overtopping volumes $(\mathrm{V})$ as well as measuring impact forces on the face of coastal structures. The PROVERBS (Oumeraci et al. 2001) project developed a parameter map enabling designers to estimate overtopping volumes and incident wave pressures for a given coastal structure geometry. The overtopping volume and behaviour is dependent on the incident wave properties. The incident wave height dictates the location of the breaking wave for a specific foreshore depth. Variation in wave heights can cause significant variation in overtopping behaviour. A parameter $h_{*}$ was introduced that determines the incident wave type dominating the overtopping performance of a structure. The fit obtained using this parameter being superior to alternatives is recommended for use with vertical seawalls (Muller et al. 2008).

$$
h_{*}=\left(\frac{h}{H_{s}}\right)\left(\frac{2 \pi h}{g T_{m}^{2}}\right)
$$

where $h$ is the water depth at the toe of the structure, $H_{s}$ is the significant wave height and $T_{m}$ is the mean wave period. Both $H_{s}$ and $T_{m}$ are taken at the toe of the structure.

When $h_{*}>0.3$, non-breaking waves dominate the overtopping behaviour. Otherwise breaking waves dominate. As the mechanics of wave downfall tend to imply that the resulting pressures are dependent on the downfall water velocity and corresponding velocity, a close relationship between overtopping behaviour and downfall pressure would seem likely. It would seem logical therefore that these mechanisms should be investigated when considering downfall pressures from breaking wave impacts. The numerical scheme discussed in this paper uses incident wave parameters that all result in an $h_{*} \leq 0.3$.

\section{Small-scale downfall pressure experiment}

Prior to the experiments at Hannover, a set of small scale experiments consisting of a series of waves breaking against a model composite breakwater were carried out (Bruce et al. 2001) Pressure measurements were taken on top of the breakwater. The maximum downfall pressure reported was $25 \mathrm{kPa}$, which is equivalent to $15 \rho g H_{s}$, with significant wave heights, $H_{s}$, of $0.06-0.113 \mathrm{~m}$ and toe water depths, $h$, of $0.085-0.24 \mathrm{~m}$. The results indicated that the highest horizontal impact pressures did not necessarily result in the highest downfall pressures. The maximum downfall pressures were usually within $60-70 \%$ of the highest impact pressure for a 1000 irregular wave series. The tank used was $20 \mathrm{~m}$ long by $0.4 \mathrm{~m}$ wide. The seawall model was $380 \mathrm{~mm}$ wide by $350 \mathrm{~mm}$ deep and roughly 280 $\mathrm{mm}$ high (Bruce et al. 2001).

The highest downfall pressures occurred over very short rise times of around $2 \mathrm{~ms}$ and were highly localised, indicating that these type of overtopping events have three dimensional effects which may not be appropriately captured by 2-D models. A prediction method was developed from this data using a Weibull distribution type probabilistic approach. The prediction tool however links impact pressure to downfall pressure, a correlation not supported by later work as discussed in the next section.

\section{Large-scale experiments at GWK (Wolters et al. 2005)}

A series of large scale experiments were carried out by Wolters et al. in 2005. The experiments consisted of a rubble mound type foreshore with a $3 \mathrm{~m}$ by $3 \mathrm{~m}$ concrete box caisson that ran the whole width of the flume $(5 \mathrm{~m})$. A series of regular waves were generated at the end of the flume and pressures both at the face and the top of the caisson were measured using Pressure Aeration Units (PAU) designed by the University of Plymouth for this experiment. A series of pressure transducers were used with the PAUs to ascertain uprush velocities. Further details on the geometry of the experimental set up are given in the next section.

The maximum downfall pressure reported was $\sim 220 \mathrm{kPa}$ which is equivalent to $12 \rho g H_{s}$. The wave characteristics used were $H_{s}$ of $1.2-1.7 \mathrm{~m}$, toe depth $h$ of $1.2-1.7 \mathrm{~m}$ and wave period $T_{m}$ of $4-10 \mathrm{~s}$. 
The Wolters et al. paper uses $H_{s}$, significant wave height, as the results given form part of a series of experiments that used both regular and irregular waves. For the purposes of this paper, $H_{i}$, will be used; this denotes incident wave height. The vertical uprush of the impacting waves reached $20 \mathrm{~m}$ leading to an estimated uprush velocity of $20 \mathrm{~m} / \mathrm{s}$. The uprush was estimated by looking at the height reached by the water jets and the time between the impact on the face of the wall and the downfall impact. The average time between the impact of the waves on the face of the wall and the resulting downfall event was less than $3 \mathrm{~s}$. The highest downfall pressures were found to occur when the uprush velocities were between $8 \mathrm{~m} / \mathrm{s}$ and $12 \mathrm{~m} / \mathrm{s}$.

The correlation between uprush velocity and the time before the downfall pressure peaked indicates that the maximum downfall pressures were caused by the water spray at the peak of the uprushing water jet. The rise time on the time-pressure graph of the downfall pressure was on average around $2 \mathrm{~ms}$ which corresponds well to the estimated rise time for the small-scale experiments though these were clearly at a different scale.

The small-scale experiments seemed to indicate that uprush velocity and wave impact pressures may be linked statistically to downfall pressures however the results reported by Wolters et al. showed no strong correlation in that direction. However, the Hannover experiment did show that the highest downfall pressures corresponded to impact pressures of $30-50 \mathrm{kPa}\left(2-3 \rho g H_{s}\right)$ whilst high impact pressure tended to result in low downfall pressures. This correlates well with the data obtained from the small - scale experiments. The data obtained from the Hannover experiments indicated that nearbreaking waves seemed to cause the highest downfall pressures not breaking waves. Based on the assumption given above relating to the tank geometry of the small-scale model, it would be reasonable to assume that the Hannover experiments are likely to be more accurate as scaling issues with the smaller models could be significant (Cuomo et al. 2010).

It was inferred that the higher uprush velocities resulting from breaking waves, caused the plumes to disintegrate further, resulting in lower downfall pressures. The ratios of uprush velocities to wave celerity resulting in large downfall pressures were around $v_{u p} / v_{c}=2.0$ to 3.5 for the water depths used. A clear relationship between downfall pressure and uprush velocity was found. This indicated that the mechanism dictating downfall pressures is more closely related to the overtopping process than to the impacting wave pressures. The form of the water jet and the process dictating its breakup would therefore seem to be of greater importance than the velocity of the downfalling water.

During the experiment a series of negative downfall pressures were measured. The largest negative pressure was $-85 \mathrm{kPa}$. Due to the very short duration of these pressures it was assumed that these were mostly due to elastic response, or decompression, of the compressed water mass during impact. This indicated that the compressibility effects are of high importance when looking at the downfall pressures from these overtopping events.

The numerical scheme proposed in this paper is designed to simulate the Hannover experiments. A good correlation between the numerical results and experimental results would indicate the ability of $\mathrm{SPH}$ to accurately model these types of wave impacts.

\section{The SPH Model}

The numerical model was developed to simulate as closely as possible the experiments carried out in the Hannover tank. Some variation is inevitable as perfectly replicating an experiment numerically is rarely possible due to the limitations of the numerical schemes, discussed further in the Limitations section. The layout of the pressure probes in the Hanover experiment consisted of a series of PAUs located vertically along the middle line of the caisson. This configuration allows for a 2-D numerical scheme to be used instead of a 3-D model as variation along the width of the tank does not appear to have been investigated in the original experiment.

\section{Model set up}

The simulation consists of a $43 \mathrm{~m}$ long tank with a $20 \mathrm{~m}$ sloping foreshore. The foreshore has a gradient of 1:4.7 for the first $10 \mathrm{~m}$ and a gradient of 1:10.7 for the next $10 \mathrm{~m}$ (see Figure 2). The slopes exactly match that of the experimental set up given by Wolters et al. However, the foreshore is a slope not the rubble mound used in the experiments. This was deemed acceptable for the purposes of this work however the effect of the roughness will need to be investigated further. 
A caisson was simulated by a $3 \mathrm{~m}$ by $3 \mathrm{~m}$ rigid body. A series of pressure sensors were located above the caisson and in front of it. The locations of the pressure probes are such that they coincide exactly with the locations of the pressure sensors reported by Wolters et al. However, as the numerical simulation allows for an infinite number of pressure probes, they have been located at a uniform spacing of $0.01 \mathrm{~m}$ along the entire length of the rigid body (see Figure 2). The pressure probes located along the face of the structure are spaced at $0.05 \mathrm{~m}$.

Due to the inaccuracies in the flow at the boundary layer, the pressure probes are located within the fluid and not exactly at the edge of the structure. The reasons for this will be discussed further later.

A series of 36 different wave sets were modelled in order to cover the range of wave conditions used in the experimental scheme. The waves are generated in the SPH model using a wave paddle which moves forward and backwards with the same frequency as the wave period (see Figure 2). To be consistent with the Wolters et al. experiments, the models used regular waves. The wave periods examined were 4, 6, 8 and $10 \mathrm{~s}$, the wave heights were 1.2, 1.45 and $1.7 \mathrm{~m}$ and the toe water depths were $1.2,1.45$ and $1.7 \mathrm{~m}$.

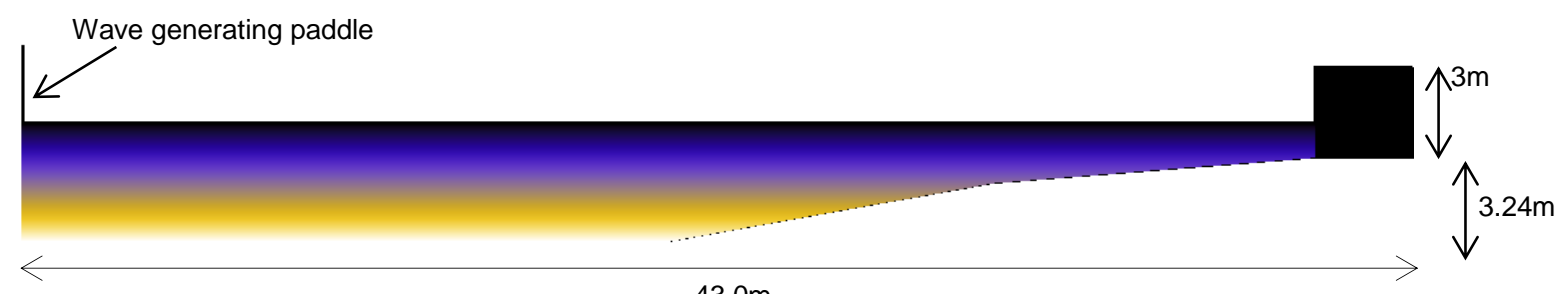

$43.0 \mathrm{~m}$

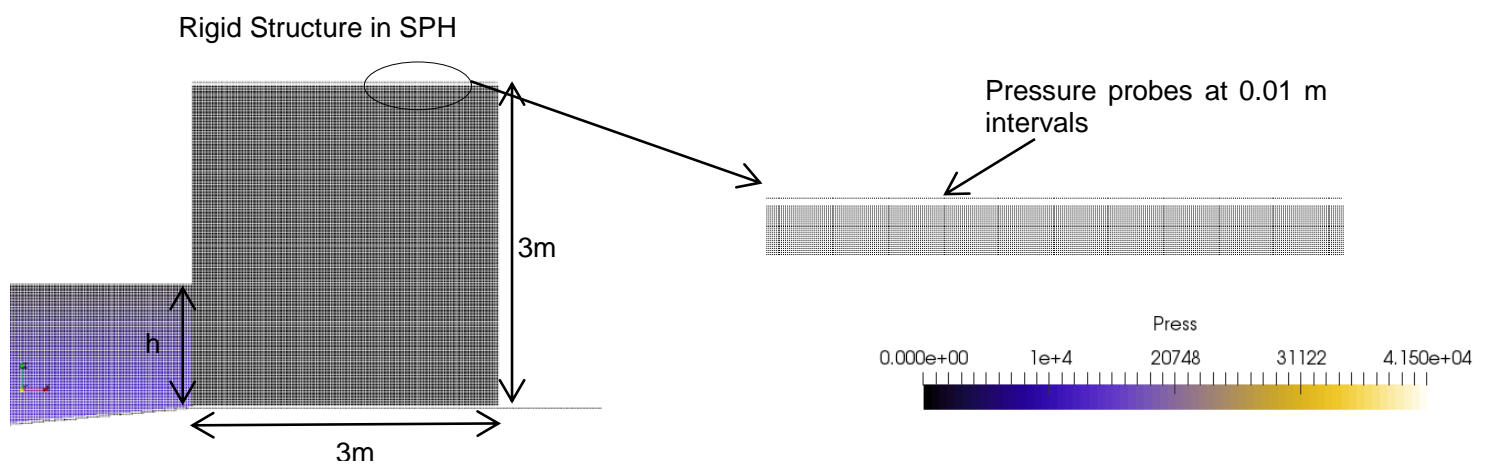

Figure 2 Set up of the numerical simulation

The simulation was run for $50 \mathrm{~s}$ of simulation time. This time frame allows for the incoming waves to interact with the reflected waves sufficiently to see the type of overtopping behaviour studied in the Hannover experiment. The numerical model does not incorporate an absorption paddle. As such, the length of the tank was extended to avoid reflection back towards the paddle; however some reflected waves did propagate back to the paddle. The incorporation of an absorption wave paddle forms part of the next phase of the work this paper introduces. Of the 36 models, 27 overtopped. The models that did not demonstrate any overtopping behaviour all corresponded to a wave period of $10 \mathrm{~s}$. Wolters et al. stated that their results are only valid for wave periods of 5 to $9 \mathrm{~s}$ as these conditions allow for the type of overtopping required. However, the results from the numerical model indicate that a period of 4 $s$ is sufficient to induce the type of overtopping required to achieve high downfall pressures.

The SPH model uses the weakly compressible formulation (Crespo et al. 2015), allowing for a variation in density of the fluid. The variation in density throughout the simulation was within $+/-1 \%$. The model was single phase so no air is modelled. A multi-phase model will form part of the next phase of this work. The SPH model was run with a particle size of $\mathrm{dp}=0.01 \mathrm{~m}$ or $\mathrm{dp} / \mathrm{H}_{\mathrm{i}}=0.0833$ for $\mathrm{H}_{\mathrm{i}}=1.2 \mathrm{~m}$. The simulation contained 1434848 to 1634698 particles depending on wave height and water depth. The particle resolution was chosen after a sensitivity analysis was carried out to determine the optimum particle resolution without too onerous a run time. The model was run using a variable time stepping scheme in order to optimise run time without the time steps being overly coarse (Gomez-Gesteira et al. 2010). Each Simulation was run on a single Tesla M2070 GPUs with 448 
cores at a clock speed of $1.15 \mathrm{GHz}$. The maximum run time was on the order of $50 \mathrm{hrs}$ depending on number of particles.

\section{Results}

\section{Pressure-time traces}

As mentioned previously, the results reported by Wolters et al. indicated that high downfall pressures did not correspond to the highest impact pressures. They also reported that the peak downfall pressures occurred within $3 \mathrm{~s}$ of the preceding wave impact. As can be seen from the graph in Figure $4 a$, the highest impact event is not always caused by the same wave impact event that results in the highest downfall pressure measurement. Whilst most of the other simulations followed that trend a few did not. This could be due to the shorter simulation time used in the numerical model however it does highlight the need for further analysis.

As can be seen in Figure $4 \mathrm{~b}$, the typical downfall events occur over very short time periods. The downfall event presented in the graph lasted for $0.2 \mathrm{~s}$. This is longer than the $2-5 \mathrm{~ms}$ reported by Wolters et al. and this is likely to be due to the resolution of the numerical simulation. The simulation had a time step of less than $10^{-4} \mathrm{~s}$ while data for the simulation is output into separate text files every $0.1 \mathrm{~s}$. It is possible to output data in shorter time scales, however the output file storage space required is onerous as well as increasing the run time and thus the frame output time was set at $0.1 \mathrm{~s}$.
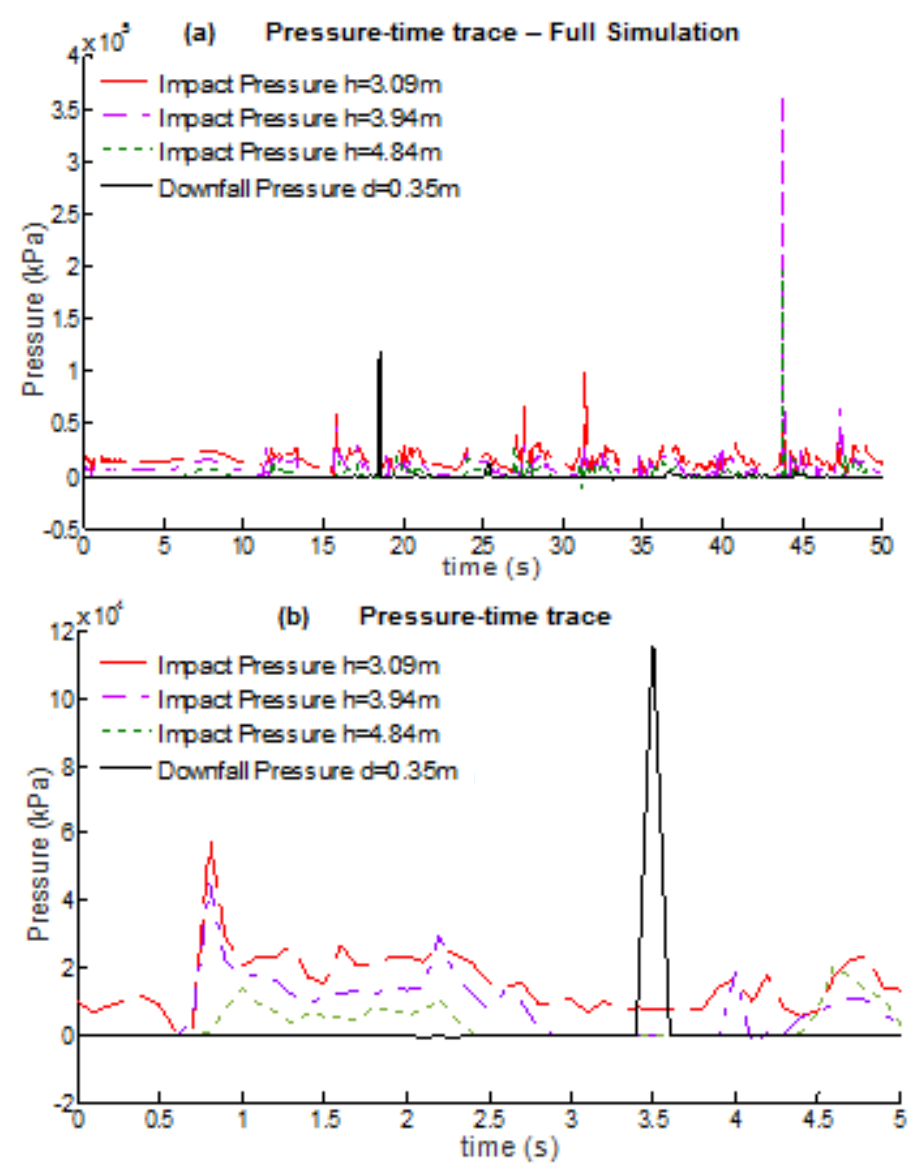

Figure 3 (a) Pressure-time trace of whole simulation; (b) For a single impact event

$$
h=1.45 \mathrm{~m}, H_{i}=1.7 \mathrm{~m}, T_{i}=4 \mathrm{~s}
$$

The capture rate of the PAUs used in the experiment was $10 \mathrm{kHz}$ and is in the same order of the time step; hence discrepancies in timescales for the predicted phenomena are not expected.

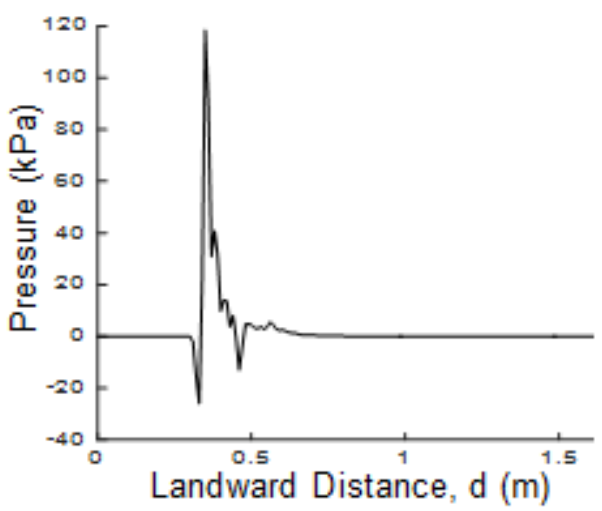

Figure 4 Spatial distribution of pressure on the deck at $t=18.5 \mathrm{~s}$

As well as being a very short event, the downfall pressures are generally very spatially specific with regards to the landward extent of the structure. As can be seen from Figure 3, the location of the high downfall pressures is confined to a small surface area. This would tend to indicate that the analysis of the landward spatial distribution of such forces is critical and that generalised overtopping volumes would be insufficient for understanding these violent events.

The snapshot of the simulation, given in Figure 5, shows main fluid body. The high pressure downfalls are due to these particles falling back down onto the top of the rigid body. This observation agrees with the observations made during the experiments which described "packets" of water at the tip of the water jets created after the initial wave impact causing the high downfall pressures. 
The simulation results also indicate that water jets generated from the interaction of the incident and reflected waves can also account for some of these severe downfall pressures (see Figure 6). This would suggest that the properties of the reflected waves near the base of seawalls could be of significant importance in quantifying the downfall pressure forces and their probability of occurrence.

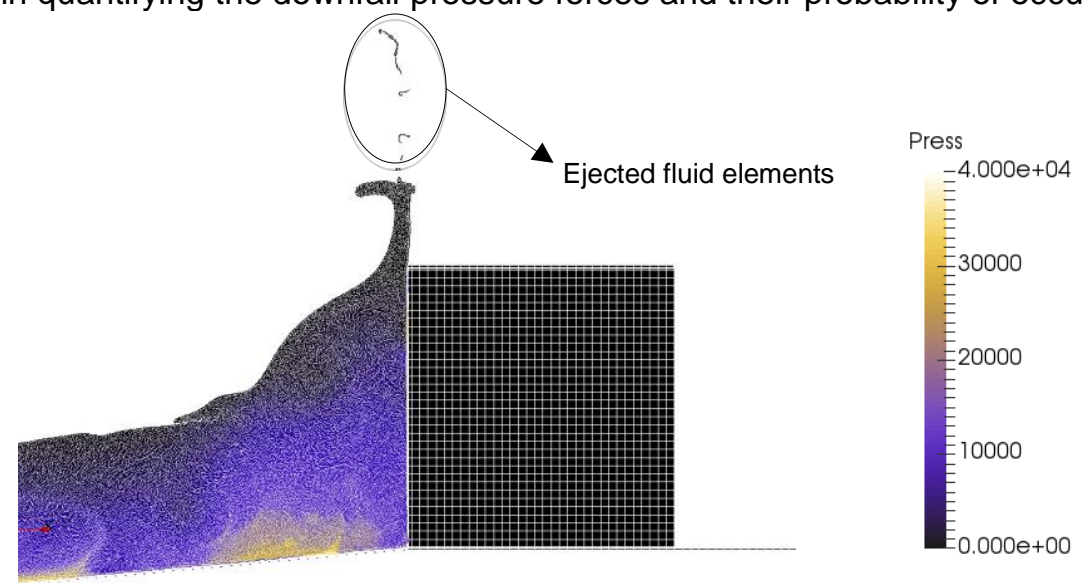

Figure 5 Ejected fluid element from wave impact; $h=1.45 \mathrm{~m}, H_{i}=1.7 \mathrm{~m}, T_{i}=4 \mathrm{~s}, t=16.5 \mathrm{~s}$

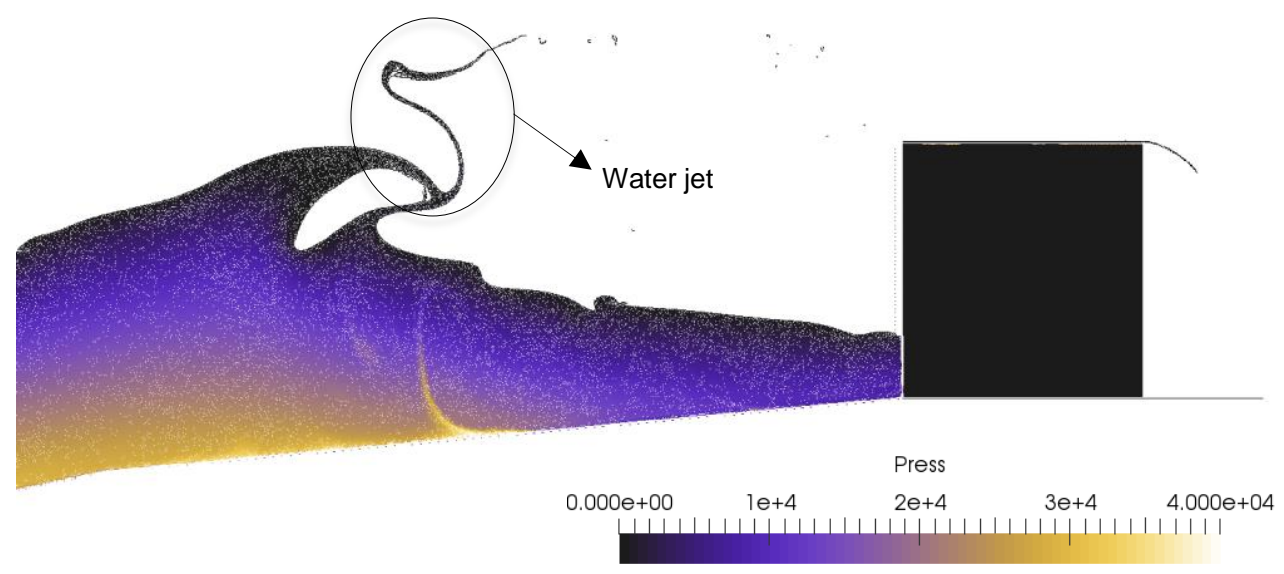

Figure 6 Water jets generated from the interaction of reflected and incident waves

$$
h=1.45 \mathrm{~m}, H_{i}=1.7 \mathrm{~m}, T_{i}=4 \mathrm{~s}, t=18.2 \mathrm{~s}
$$

\section{Pressure maxima}

For each simulation, the maximum downfall pressure was extracted along with the location and time of the event. From this the highest impact pressure for the preceding wave impact event was identified. This was achieved by isolating the peak impact pressure which occurs within $5 \mathrm{~s}$ of the downfall pressure (see Figure 3). These have been graphed and Figure 7 shows the results for each simulation overlaid over the experimental results reported by Wolters et al. The results from the models that corresponded with zero overtopping have been removed as the graph is set to a log scale and therefore cannot plot zero value points. The results from the numerical model generally agree with the distribution of the scatter obtained from the experiments. None of the points exactly coincide with the experimental data. However, as no specific wave properties are given for any of the experiments, this is expected as the wave properties used in the numerical simulation were chosen to reflect the range given in Wolters et al. The mean, median and standard deviation were calculated for the uprush velocities of the SPH and Experimental data. The mean and median for the SPH data were within 7\% of the experimental data. The standard deviation was within 38\% however the SPH simulation has fewer data points than the experiments (24 compared to 35 ). With such a small sample size, a change in the number of data points within a comparable data range can affect the standard deviation significantly and likely explains the discrepancy. 


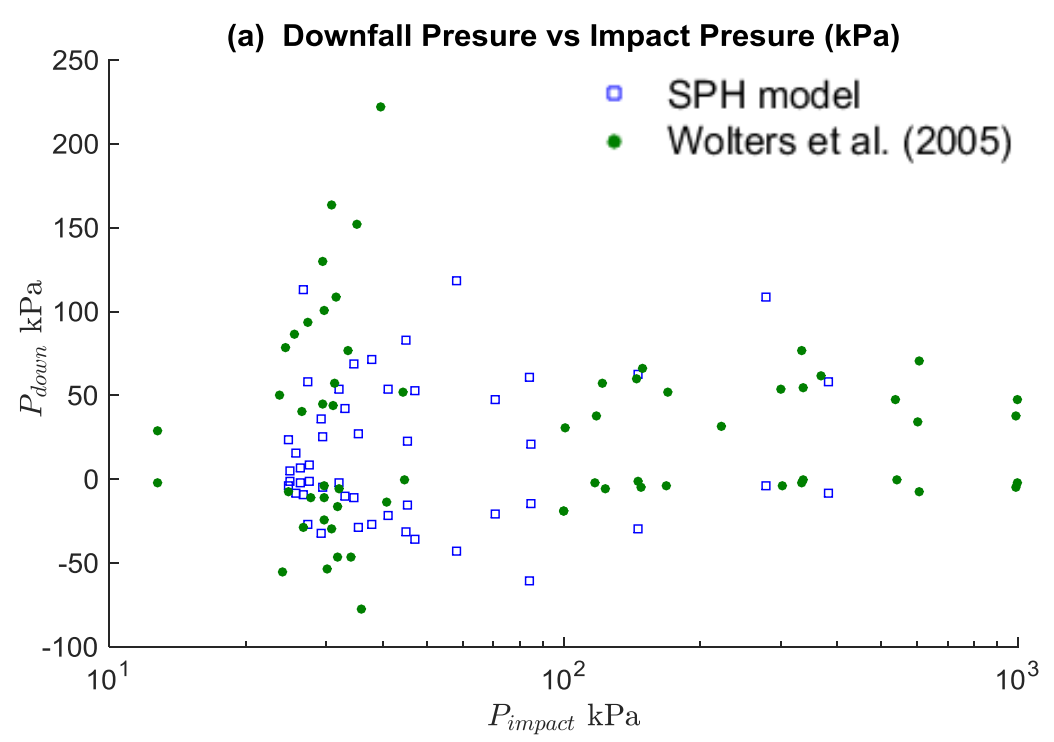

(b) Downfall Pressure (kPa) vs Uprush Velocity $(\mathrm{m} / \mathrm{s})$

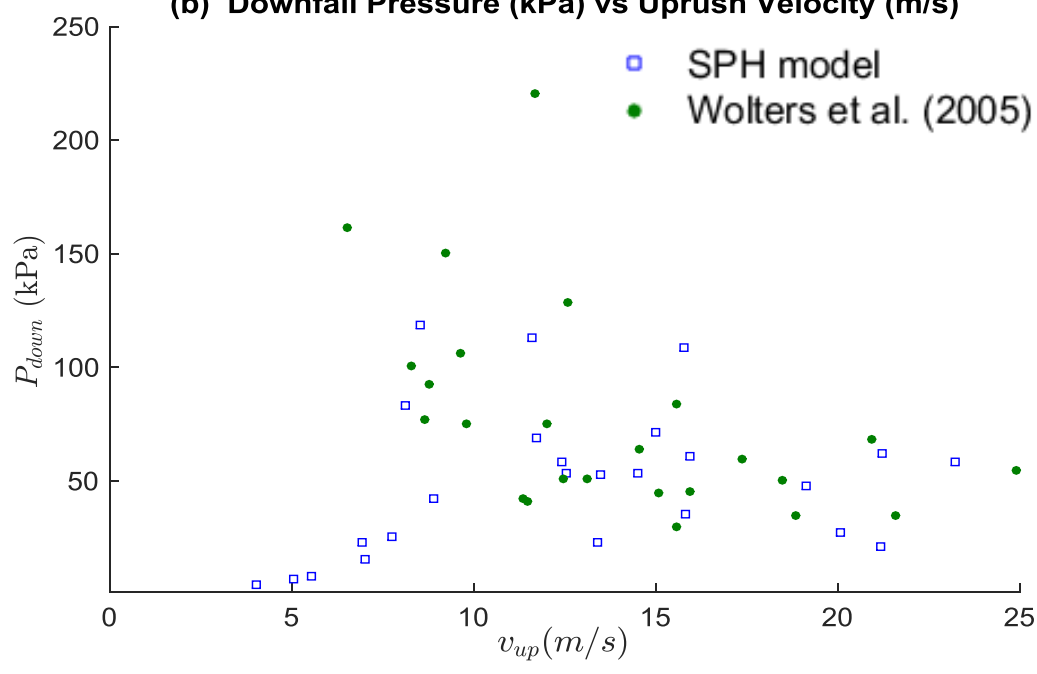

Figure 7 Comparison of numerical and experimental pressure data
Wolters et al. suggested, unlike the results from the small-scale experiments, that there would be no direct correlation between impact pressures or uprush velocities and downfall pressures. As can be seen in Figure 7 , there is clearly no direct correlation, however the scatter in Figure $7 \mathrm{~b}$ may have some statistical correlation as proposed by Bruce et al, this would require detailed correlation analysis to ascertain.

The graph showing impact pressures against downfall pressures (Figure 7a) has both positive and negative values plotted for the downfall pressure. Indeed, some reasonably large negative pressures were measured throughout the simulation. The negative pressures plotted are the ones which occurred within the same impact event as the downfall pressure. They were usually measured very soon before or after the downfall pressure (0.1$0.3 \mathrm{~s}$ ). Negative pressure usually correlates to suction forces due to the displacement of the fluid away from the structure. This would not be unreasonable to expect as the high energy impacts observed in these events would likely cause some of the fluid particles, depending on mass, to rebound on impact.

As mentioned in the previous section, Figure 7a clearly shows that the highest downfall pressures do not always correspond to the highest horizontal impact pressures in the preceding impact event. The high downfall pressures are generally concentrated between $25 \mathrm{kPa}$ and $60 \mathrm{kPa}$. This corresponds relatively well with the range of $30-50 \mathrm{kPa}$ reported by Wolters et al. Both data sets get the highest downfall pressures for impact forces of $2-3 \rho g H_{i}$ which would indicate that the numerical model is replicating the behaviour of the impacting waves and the resulting white water overtopping with an acceptable degree of accuracy. It should be noted that the highest impact force measured during a simulation was usually larger than the highest downfall pressure. It would be hard to relate the highest impact pressure with the downfall pressures measured as the ratio of the downfall pressures to impact pressures was anywhere between $15-75 \%$ with no pattern apparent.

By looking at Figure $7 \mathrm{~b}$ in more detail, the velocities corresponding to the high downfall pressures are 8-12 $\mathrm{m} / \mathrm{s}$ which corresponds well to the velocities quoted by Wolters et al. However, in order to infer specific conclusions about the accuracy of the SPH velocity field during the impact events, more indepth analysis and comparison with experimental measurements should be carried out as the velocities were interpolated around a series of points near the structure and the rest of the velocity field is ignored. 


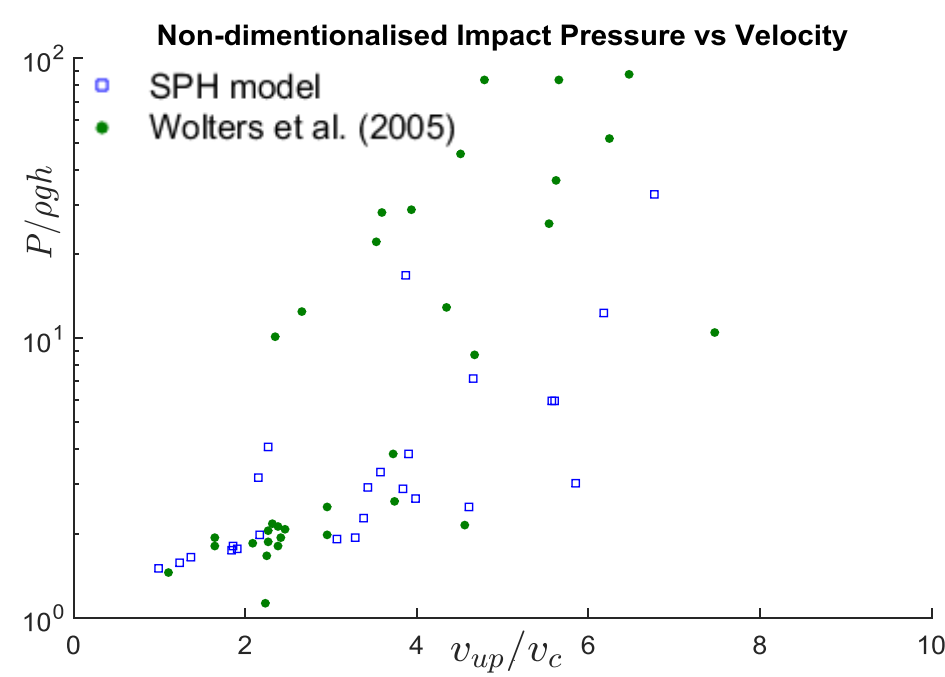

Figure 8 Non-dimensionalised impact pressure and velocity

In Figure 8, the velocity has been nondimensionalised against the wave celerity, approximated using the inshore wave celerity equation $v_{c}=\sqrt{g h}$ with $\mathrm{h}$ being the water depth at the toe of the structure. Impact pressure has been nondimensionalised using $\mathrm{h}$ not $\mathrm{H}$, as is usual, as the numerical data was developed to match the experimental data reported by Wolters et al. Again there is significant scatter in the results and no correlation with an acceptable $R^{2}$ value could be found. This would suggest that although the graph could tend to indicate a potential for a correlation between impact pressures and uprush velocities, the current data range is insufficient to determine this correlation. The results obtained in the Hannover experiment and the numerical results indicate a very similar trend. As stated previously, perfect agreement is not feasible as the exact wave parameters used in the experiments are unknown. However, the numerical results do not support the idea of a clear correlation between the two parameters proposed by Wolters et al.

The lack of any clear correlation between the uprush velocity, impact pressure and downfall pressure would support the theory, proposed by Wolters et al., that the mechanism dictating the downfall pressure and distribution would not be as closely linked to the wave impact events as previously proposed. A more complete analysis would be required however in order to draw any firm conclusions.

\section{Discussion}

\section{Model Limitations}

$\mathrm{SPH}$ is a numerical model, and as such has various limitations which will reduce the accuracy or realism of the results obtained. This is partly due to the numerical formulation of discrete functions, a problem common to any numerical model, and partly specific to the fact that it is a Lagrangian model using discrete particles instead of a mesh.

As mentioned previously, the pressure probes used in this model to obtain pressure values for the fluid had to be placed above the structure and not on its surface. The reason for this is down to the type of boundary used for the structure, the boundary condition implemented within DualSPHysics causes the fluid to separate from the boundary and a gap appears which ultimately means there can be cases where there are no particles within the interpolation distance of the boundary. This can be reduced using higher resolutions, however this is computationally expensive. As pressure is locally isobaric it therefore can be extrapolated that the pressure within the fluid at the boundary is going to reflect the pressure applied to the structure itself.

The resolution of the model was chosen as a balance between good results and an acceptable computational time. However, it has become evident that in order to be able to better assess the physical behaviour of the fluid during violent overtopping events, a higher resolution near the breakwater would be required. The agreement obtained between the experimental results and numerical results was sufficient to validate the principle and as such the resolution used was maintained at $0.01 \mathrm{~m}$.

\section{Conclusions}

The aim of this paper was to assess the applicability of the SPH model, specifically the DualSPHysics code, to violent wave impacts and the subsequent occurrence of downfall pressures. Being a relatively new numerical model, the need to validate it against experimental data was identified. However, as can be seen from the overview given of previous work, few experimental schemes exist with published 
data that can be applied to this problem. The Hannover flume experiment was identified as a viable test case for the initial investigation.

The results presented indicate that the numerical model achieves a relatively high degree of agreement with experimental data with the mean and median of the uprush velocities within $7 \%$ of the experimental data. Some deviation is evident however. The deviation could be due to the limitations identified in the discussion section whilst some may be a result of the experimental limitations and inherent variability of this kind of phenomenon.

In conclusion it would seem that the SPH method is able to model the highly non-linear flow typical of violent wave events.

\section{Future work}

The work presented here is part of an ongoing scheme of research at the University of Manchester involving use of SPH to model violent wave overtopping events. The limitations discussed in the previous section are all areas of ongoing investigation.

\section{Acknowledgement}

The authors would like to thank the ESPRC and the University of Manchester's Research Impact Scholarship for supporting and funding this work.

\section{References}

Altomare, C., Crespo, A.J.C., Dominguez, J.M., Gomez-Gesteira, M., Suzuki, T. \& Verwaest, T., 2015. Applicability of Smoothed Particle Hydrodynamics for estimation of sea wave impact on coastal structures. Coastal Engineering, 96, pp.1-12. Available at: http://dx.doi.org/10.1016/j.coastaleng.2014.11.001.

Altomare, C., Oshima, Y., Chen, X., Crespo, A.J.C. \& Suzuki, T., 2015. Study of the overtopping flow impacts on multifunctional sea dikes in shallow foreshores with an hybrid numerical model. $E$ proceedings of the 36th IAHR World Congress 28 June - 3 July, 2015, The Hague, the Netherlands, (October).

Altomare, C. \& Suzuki, T., 2013. Coupling between SWASH and SPH for real coastal problems. In 9th International SPHERIC workshop.

Arns, A., Wahl, T., Dangendorf, S. \& Jensen, J., 2015. The impact of sea level rise on storm surge water levels in the northern part of the German Bight. Coastal Engineering, 96, pp.118-131. Available at: http://dx.doi.org/10.1016/j.coastaleng.2014.12.002.

Bruce, T., Franco, L., Alberti, P., Pearson, J. \& Allsop, N.W.H., 2001. Violent wave overtopping: discharge throw velocities, trajectories and resulting crown deck loading. In Ocean Wave Measurement and Analysis. American Society of Civil Engineers, pp. 1783-1796.

Committee on Climate Change, 2017. HM Government UK Climate Change Risk Assessment 2017 UK Climate Change Risk Assessment 2017, London.

Crespo, A.J.C., Domínguez, J.M., Rogers, B.D., Gómez-Gesteira, M., Longshaw, S., Canelas, R., Vacondio, R., Barreiro, A. \& García-Feal, O., 2015. DualSPHysics: Open-source parallel CFD solver based on Smoothed Particle Hydrodynamics (SPH). Computer Physics Communications, 187, pp.204-216. Available at: http://dx.doi.org/10.1016/j.cpc.2014.10.004.

Cunningham, L. \& Burgess, A., 2012. Design and construction of the tower headland wave walls, Blackpool, UK. Proceedings of the Institution of Civil Engineers - Civil Engineering, 165(4), pp.171-178.

Cunningham, L.S., Rogers, B.D. \& Pringgana, G., 2014. Tsunami wave and structure interaction: an investigation with smoothed-particle hydrodynamics. Proceedings of the Institution of Civil Engineers - Engineering and Computational Mechanics, 167(EM3), pp.126-138.

Cuomo, G., Allsop, W. \& Takahashi, S., 2010. Scaling wave impact pressures on vertical walls. Coastal Engineering, 57(6), pp.604-609.

Dominguez, J.M.L., Suzuki, T., Altomare, C., Crespo, a J.C. \& Gómez-Gesteira, M., 2014. Hybridisation of a wave propagation model (SWASH) and a meshfree particle method (SPH) for real applications. 3rd IAHR Europe Congress: book of proceedings, 2014, Porto - Portugal, (1), pp.1-10.

Gomez-Gesteira, M., 2009. State-of-the-art of classical SPH for free-surface flows. Journal of Hydraulic Research, 48(extra), p.0. 
Health and Safety Executive, 2000. Review of Greenwater and Waveslam Design \& Specification Requirements for FPSO/FSU's. Offshore technology report - OTO 2000004.

Koukouvinis, P.K., Anagnostopoulos, J.S. \& Papantonis, D.E., 2013. An improved MUSCL treatment for the SPH-ALE method: comparison with the standard SPH method for the jet impingement case. Int. J. Numer. Meth. Fluids, 71, pp.1152-1177.

Marongiu, J.-C., Leduc, J. \& Schaller, M., 2011. GPU implementation of a SPH-ALE fluid dynamics solver. In 6th International Spheric Workshop. Hamburg.

Marrone, S., Antuono, M., Colagrossi, A., Colicchio, G., Le Touzé, D. \& Graziani, G., 2011. Delta-SPH model for simulating violent impact flows. Computer Methods in Applied Mechanics and Engineering, 200, pp.1526-1542.

McCabe, M., Stansby, P.K., Rogers, B.D. \& Cunningham, L.S., 2014. Boussinesq modelling of tsunami and storm wave impact. Proceedings of the Institution of Civil Engineers - Engineering and Computational Mechanics, 167(EM3), pp.106-116.

McCabe, M. V., Stansby, P.K. \& Apsley, D.D., 2013. Random wave runup and overtopping a steep sea wall: Shallow-water and Boussinesq modelling with generalised breaking and wall impact algorithms validated against laboratory and field measurements. Coastal Engineering, 74, pp.3349. Available at: http://dx.doi.org/10.1016/j.coastaleng.2012.11.010.

Van der Meer, J.W., Allsop, N.W.H., Bruce, T., De Rouck, J., Kortenhaus, A., Pullen, T., Schüttrumpf, H., Troch, P. \& Zanuttigh, B., 2016. EurOtop 2016: Manual on wave overtopping of sea defences and related structures An overtopping manual largely based on European research, but for worldwide application. , p.264. Available at: http://www.overtopping-manual.com/index.html.

Muller, G., Allsop, W., Bruce, T., Kortenhaus, A., Pearce, A. \& Sutherland, J., 2008. The occurrence and effects of wave impacts. Proceedings of the Institution of Civil Engineers - Maritime Engineering, 160(4), pp.167-173. Available at: http://dx.doi.org/10.1680/maen.2007.160.4.167.

Oumeraci, H., Kortenhaus, A., Allsop, N.W.H., Groot, M. de, Crouch, R., Vrijling, H. \& Voortman, H., 2001. Probabilistic Design Tools for Vertical Breakwaters,

Pringgana, G., Cunningham, L.S. \& Rogers, B.D., 2016. Modelling of tsunami-induced bore and structure interaction. In Proceedings of the Institution of Civil Engineers - Engineering and Computational Mechanics. Institute of Civil Engineers, pp. 109-125.

Wolters, G., Müller, G., Bruce, T. \& Obhrai, C., 2005. Large-scale experiments on wave downfall pressures. Proceedings of the Institution of Civil Engineers - Maritime Engineering, 158(MA4), pp.137-145. Available at: http://dx.doi.org/10.1680/maen.2005.158.4.137. 